\title{
Perceptions of Pharmacy and Other Health Professional Students toward Interprofessional Education
}

\author{
Azieb Ogbaghebriel ${ }^{1 *}$, Jude AlHuwaidi ${ }^{2,1}$, Raneem AlZeer ${ }^{1}$ \\ ${ }^{1}$ College of Pharmacy, Princess Nourah bint Abdulrahman University, Riyadh, SAUDI ARABIA. \\ ${ }^{2}$ Clinical Pharmacy Department, King Fahad Medical City, Riyadh, SAUDI ARABIA.
}

\begin{abstract}
Background: Interprofessional Education (IPE) equips students with a background for multidisciplinary collaboration in health care provision and its success could be influenced by students' attitudes. Objectives: To assess the readiness and perceptions of pharmacy and other health professional students toward IPE. Methods: A survey was conducted on students of Pharmacy, Medicine, Nursing, Dentistry and Health and Rehabilitation Sciences (HRS) utilizing the 19-item instrument for assessing the Readiness for Interprofessional Learning Scale (RIPLS) with four subscales. Data analysis was done on individual items, the sub-scales and total scores using descriptive and inferential statistics. Results: Individual item scores were above 4 out of 5 for most of the RIPLS items except for negative professional identity and roles and responsibility. Overall total mean score was $76.40 \pm 10.30$ out of 95 , with no significant difference among the colleges. On the subscale of professional identity, Dentistry and Nursing scores were significantly lower. On attitudes towards roles of nurses and therapists, scores of Nursing and HRS showed significant disagreement with those of Medicine and Dentistry, but not with Pharmacy. Overall, only $28 \%$ of the participants had prior knowledge of IPE, with Pharmacy having relatively higher percentage $(37.4 \%)$. There was no significant correlation of the RIPLS scores with either age or year of study. Conclusion. Overall, students' attitude toward IPE was positive. Differences in perceptions of professional identity, roles and responsibilities among some professions require attention of educators since understanding of such attributes is vital for creating effective healthcare teams.
\end{abstract}

Key words: Interprofessional education, Health professions, Pharmacy students, Middle East, Perceptions, Readiness.

\section{INTRODUCTION}

Healthcare is given by a large number of diverse experts in which pharmacists play a vital role. The role of pharmacists within the healthcare provider team has become more evident with their expanding role, which evolved since the formulation of Hepler and Strand's concept of pharmaceutical care. ${ }^{1}$ Understanding of one's roles within a team and the perceptions of others on your roles is a very important contributor to the outcome of team work, for which interprofessional Education (IPE) is believed to greatly contribute. ${ }^{2}$ Definitions of IPE are varied but they all site the involvement of two or more professions, together creating a collaborative learning environment. ${ }^{3} \mathrm{IPE}$ as an innovative strategy was highlighted by the WHO, which was based on earlier progress made on the concept of IPE being a vital aspect of primary health care. ${ }^{4}$ Furthermore, in 2010, a WHO framework emphasized the importance of incorporating IPE to prepare a health workforce that can handle complex challenges. ${ }^{5}$ Various studies have also been conducted that provided evidence for the contribution of IPE to enable knowledge, skills and behaviours necessary for cooperative multidisciplinary
Submission Date: 25-02-2021; Revision Date: 14-04-2021; Accepted Date: 02-07-2021

DOI: 10.5530/ijper.55.3.166 Correspondence: Azieb Ogbaghebriel College of Pharmacy, Princess Nourah bint Abdulrahman University, Riyadh, Saudi Arabia, 13415 Phone: +966559498970 E-mail: adogbagherbriel@ pnu.edu.sa

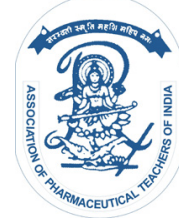

www.ijper.org 
work. ${ }^{6-8}$ The Institute of Medicine Committee on Health Professions Education recommends incorporating IPE throughout the entire curriculum. ${ }^{9}$ Despite the fact that IPE has been extensively reported in the literature, many of the studies were conducted in the developed countries with some information emerging recently from the developing world including the Middle East. ${ }^{10-14}$ Furthermore, despite the importance of IPE for all health professions, the studies on IPE predominantly represent the fields of medicine and nursing. ${ }^{6,15,16}$ With the increased acceptance of IPE in the development of team-oriented future health professionals and its increased requirement in accreditation standards, it is becoming more and more important to incorporate IPE in the curricula of most health professions. With the adoption of the concept of pharmaceutical care leading to the changing roles and responsibilities of pharmacists, efforts are emerging to incorporate IPE in Pharmacy curricula, including in developing countries. ${ }^{14,17-19}$

It has been suggested that the success of interprofessional education initiatives is influenced by the attitudes and readiness of students. ${ }^{10-12,20-22}$ Therefore, assessing the perceptions and attitude of students in a wide range of health professions to shared learning can indicate their readiness for IPE. Such assessments, therefore, would have important contributions towards the proper design and implementation of IPE initiatives. It is with this background that the present study was initiated. Thus, the objective of this study was to examine the perceptions and readiness of students from five health colleges: pharmacy, medicine, dentistry, nursing and health and rehabilitation sciences to IPE and to explore any differences among the professions, which might affect the development and design as well as the successful implementation of IPE programs.

\section{METHODS}

This was a cross-sectional study utilizing a standard validated questionnaire conducted at the health colleges of Princess Nourah bint Abdulrahman University in Riyadh, Saudi Arabia, which is probably the largest all-female university with a total of approximately 39,000 female students in 18 colleges and institutes including five health colleges. All the five health colleges, namely Pharmacy, Medicine, Dentistry, Nursing and Health and Rehabilitation Sciences (HRS) were included for data collection. The target populations of students were those who were in the first professional year of the respective health colleges up to the final professional year. The first professional year is the second year of university, as students join the health colleges after completion of one common foundational year of the university. Students of the foundational year and those in the internship year were excluded from the study. Since the length of program in the various disciplines varies, the final professional year excluding the internship year is: $3^{\text {rd }}$ professional year for Nursing and HRS; $4^{\text {th }}$ professional year for Pharmacy; and $5^{\text {th }}$ professional year for Medicine and Dentistry. There were a total of 2400 students at the time of the survey in the five colleges and a sample size of 332 was calculated using 95\% confidence and 5\% error margin. Sample sizes were then allocated in proportion to the student population size of each college. Assuming a 25\% non-response rate, 440 questionnaires were distributed. A self-administered questionnaire was used for data collection from consenting students. The study objectives and meaning of IPE were explained along with the consent request. A standard validated questionnaire of McFayden et al. the RIPLS consisting of 19 items covering 4 subscales, was used to collect data. ${ }^{23}$

The four subscales ${ }^{23}$ which identify and assess different aspects of IPE are categorized as follows:

- Item 1-9, Teamwork and Collaboration

- Item 10-12, Negative Professional Identity

- Item 13-16, Positive Professional Identity

- Item 17-19, Roles and Responsibility.

A 5-point Likert scale ranging from 1 (strongly disagree) to 5 (strongly agree) was used to collect responses to the questionnaire items. On analysis, scoring was reversed for negative statement items. Demographic information on age, college and study level was also collected. All respondents were female because Princess Nourah University is an all-female university. Before administering the questionnaire, it was tested with a pilot of sets of 5 students from each college to ensure its clarity.

Statistical analysis was done using SPSS, version 23. Mean subscale scores among colleges were compared using ANOVA and post-hoc analysis using Fisher's LSD. Pearson correlation analysis was performed to assess for possible association of the RIPLS scores with age and level of university study. Difference was considered significant for $p \leq 0.05$.

Ethical approval was secured from the IRB of the University.

\section{RESULTS AND DISCUSSION}

\section{Demographic information}

Out of the total 440 questionnaires distributed 402 were completed resulting in $91.4 \%$ response rate. Each college was allocated a number of questionnaires proportional 
to the total number of its students. The proportion of students as a percentage of the total student number in all the health colleges, which was 2400 at the time of the survey, was as follows: HRS (29\%); Pharmacy (24\%); Nursing (23\%); Medicine (15\%); and Dentistry (9\%). As can be seen in Table 1, the percentage of respondents in this study was also in line with the percentage of the number of students in each college. The distribution of respondents by college ranged from $11.4 \%$ in Dentistry to $26.6 \%$ in HRS. Table 1 also shows the distribution of participants by age groups. The majority of respondents were from age group 20-22 years (69.4\%) followed by those aged $23-25$ years $(21 \%)$ and less than 20 years of age $(8.4 \%)$, with only $1.3 \%$ constituting those above the age of 25 years. Moreover, as shown in Table 1, the highest proportion of respondents $(35.8 \%)$ were in their $1^{\text {st }}$ professional year, which corresponds to the $2^{\text {nd }}$ year of their university studies, followed by about equal proportion of those in the $2^{\text {nd }}$ (about 25\%) and $3^{\text {rd }}$ (about 27\%) professional years. Respondents in the $4^{\text {th }}$ and $5^{\text {th }}$ professional years constituted only $9 \%$ and $3 \%$ respectively, but the number of programs that run 4 and 5 year professional programs are also fewer, namely Pharmacy (4 professional years) and Medicine and Dentistry ( 5 professional years) which are followed by an additional internship year. None of the interns were included in the study.

\section{Prior knowledge of IPE}

Participant responses to whether they had prior knowledge of IPE before this survey indicated that the majority $(72 \%)$ did not have prior knowledge of IPE, with only $28 \%$ being aware of IPE before this survey. As indicated in Table 1, the break down of prior IPE knowledge by college showed that Pharmacy had the highest proportion of students (37.4\%) with prior knowledge of IPE, followed by Dentistry (30.4\%), Nursing (26.4\%), HRS $(24.3 \%)$ and Medicine (20.3\%).

\section{RIPLS Item Scores}

Table 2 reveals scores of each item of the questionnaire as mean $\pm \mathrm{SD}$ of all participants $(\mathrm{N}=402)$. Minimum and maximum possible scores for each item are 1 and 5 respectively. The maximum mean score for this survey was 4.67 for RIPLS item 7, which indicates that students strongly agree with the need for each other's respect as well as trust. As shown in Table 2, overall students scored above 4 for the majority of the items of the RIPLS except for items 10-12 (related to negative professional identity) and 17-19 (related to roles and responsibilities) where the scores were below 4 . The response scores of above 4 for the majority of the

\begin{tabular}{|c|c|c|}
\hline Variable & Descriptor & N (\%) \\
\hline \multirow[t]{4}{*}{ Age (years) } & $<20$ & $33(8.4)$ \\
\hline & $20-22$ & $274(69.4)$ \\
\hline & $23-25$ & $83(21)$ \\
\hline & $>25$ & $5(1.3)$ \\
\hline \multirow[t]{5}{*}{ College } & HRS & $107(26.6)$ \\
\hline & Pharmacy & $99(24.6)$ \\
\hline & Nursing & $91(22.6)$ \\
\hline & Medicine & $59(14.7)$ \\
\hline & Dentistry & $46(11.4)$ \\
\hline \multirow{5}{*}{$\begin{array}{c}\text { Year of study in } \\
\text { the professional } \\
\text { program }\end{array}$} & $1^{\text {st }}$ & $144(35.8)$ \\
\hline & $2^{\text {nd }}$ & $100(25)$ \\
\hline & $3^{\text {rd }}$ & $109(27)$ \\
\hline & $\begin{array}{c}4^{\text {th }} \text { (only Medicine, Dentistry \& } \\
\text { Pharmacy) }\end{array}$ & $36(9)$ \\
\hline & $\begin{array}{c}5^{\text {th }} \text { (Only Medicine \& } \\
\text { Dentistry) }\end{array}$ & $13(3)$ \\
\hline \multirow{6}{*}{$\begin{array}{l}\text { Prior knowledge } \\
\text { of IPE** }\end{array}$} & Pharmacy & $37(37.4)$ \\
\hline & Dentistry & $14(30.4)$ \\
\hline & Nursing & $24(26.4)$ \\
\hline & HRS & $26(24.3)$ \\
\hline & Medicine & $12(20.3)$ \\
\hline & Total & $113(28.1)$ \\
\hline
\end{tabular}

*All students had a year of pre-professional university study, thus the first professional year corresponds to the second university year.

** The percentage is calculated relative to the number of respondents in the respective college.

questionnaire items, are indicative of students having positive attitudes towards teamwork and collaboration (items 1 to 9) as well as shared learning (items 13 to16). However, the items that revealed relatively lower scores, which were reflected with the specific items attributed to the individual professional identities and roles and responsibilities, deserve particular attention possibly with further qualitative investigation to identify the reasons for the less positive attitudes.

\section{RIPLS Sub-Scale Scores}

The four sub-scales of the RIPLS are important for the assessment of student attitudes in alignment with the core competencies needed in IPE. Table 3 presents subscale mean scores and overall RIPLS score of each college, as well as the total mean score for all the colleges combined. The overall mean score of RIPLS for all the colleges combined was $76.40 \pm 10.30$ out of a maximum possible score of 95 . The individual college total RIPLS scores were close to each other, with no significant difference, which ranged from $75.22 \pm 11.15$ (for HRS) to $77.67 \pm 7.07$ (for Dentistry). Conflicting reports are present in the literature regarding differences 


\begin{tabular}{|c|c|c|}
\hline RIPLS Item & Mean Score & \pm SD \\
\hline 1- Learning with other students will help me become a more effective member of a healthcare team & 4.35 & 0.729 \\
\hline 2- Patients would ultimately benefit if health care students worked together to solve patient problems. & 4.38 & 0.675 \\
\hline 3- Shared learning with other healthcare students will increase my ability to understand clinical problems & 4.50 & 0.621 \\
\hline 4- Learning with healthcare students before qualification would improve relationships after qualification. & 4.34 & 0.725 \\
\hline 5- Communication skills should be learned with other healthcare students. & 4.33 & 0.749 \\
\hline 6- Shared learning will help me to think positively about other professionals & 4.41 & 0.700 \\
\hline 7- For small-group learning to work, students need to trust and respect each other. & 4.69 & 0.544 \\
\hline 8- Team-working skills are essential for all healthcare students to learn. & 4.51 & 0.686 \\
\hline 9- Shared learning will help me to understand my own limitations. & 4.21 & 0.871 \\
\hline 10- I do not want to waste my time learning with other healthcare students. & 3.51 & 1.264 \\
\hline 11- It is not necessary for undergraduate healthcare students to learn together & 3.36 & 1.265 \\
\hline 12- Clinical problem-solving skills can only be learned with students from my own department. & 3.20 & 1.269 \\
\hline $\begin{array}{l}\text { 13- Shared learning with other healthcare students will help me to communicate better with patients and other } \\
\text { professionals. }\end{array}$ & 4.51 & 0.668 \\
\hline 14- I would welcome the opportunity to work on small-group projects with other healthcare students. & 4.24 & 0.882 \\
\hline 15- Shared learning will help to clarify the nature of patient problems. & 4.37 & 0.678 \\
\hline 16- Shared learning before qualification will help me become a better team worker. & 4.39 & 0.708 \\
\hline 17- The function of nurses and therapists is mainly to provide support for doctors & 3.45 & 1.358 \\
\hline 18- I am not sure what my professional role will be. & 2.57 & 1.301 \\
\hline 19- I have to acquire much more knowledge and skills than other healthcare students. & 3.65 & 1.193 \\
\hline
\end{tabular}

\begin{tabular}{|c|c|c|c|c|c|c|c|c|}
\hline \multirow[t]{2}{*}{ Subscales } & \multirow{2}{*}{$\begin{array}{c}\text { Nursing } \\
\text { Mean (SD) }\end{array}$} & \multirow{2}{*}{$\begin{array}{l}\text { Medicine } \\
\text { Mean (SD) }\end{array}$} & \multirow{2}{*}{$\begin{array}{l}\text { HRS } \\
\text { Mean } \\
\text { (SD) }\end{array}$} & \multirow{2}{*}{$\begin{array}{l}\text { Pharmacy } \\
\text { Mean (SD) }\end{array}$} & \multirow{2}{*}{$\begin{array}{l}\text { Dentistry } \\
\text { Mean (SD) }\end{array}$} & \multirow{2}{*}{$\begin{array}{c}\text { All } \\
\text { Colleges } \\
\text { Mean (SD) }\end{array}$} & \multicolumn{2}{|c|}{ ANOVA } \\
\hline & & & & & & & $\mathbf{F}$ & $p$ \\
\hline $\begin{array}{l}\text { Teamwork \& } \\
\text { collaboration }\end{array}$ & $\begin{array}{l}39.43 \\
(7.11)\end{array}$ & $39.63(6.41)$ & $\begin{array}{l}38.74 \\
(6.43)\end{array}$ & $\begin{array}{l}39.76 \\
(5.30)\end{array}$ & $\begin{array}{l}40.63 \\
(5.15)\end{array}$ & $\begin{array}{l}39.49 \\
(6.20)\end{array}$ & 0.838 & 0.502 \\
\hline $\begin{array}{c}\text { Negative } \\
\text { professional identity }\end{array}$ & $\begin{array}{c}9.53 \\
(3.99)\end{array}$ & $\begin{array}{c}9.64 \\
(3.34)\end{array}$ & $\begin{array}{l}10.34 \\
(3.25)\end{array}$ & $\begin{array}{l}10.74 \\
(3.28)\end{array}$ & $\begin{array}{c}8.93 \\
(3.86)\end{array}$ & $\begin{array}{c}9.99 \\
(3.56)\end{array}$ & 2.939 & $0.020^{*}$ \\
\hline $\begin{array}{l}\text { Positive professional } \\
\text { identity }\end{array}$ & $\begin{array}{l}17.69 \\
(3.27)\end{array}$ & $\begin{array}{l}17.32 \\
(3.03)\end{array}$ & $\begin{array}{l}17.22 \\
(2.83)\end{array}$ & $\begin{array}{l}17.30 \\
(2.50)\end{array}$ & $\begin{array}{l}18.04 \\
(2.29)\end{array}$ & $\begin{array}{l}17.46 \\
(2.83)\end{array}$ & 0.949 & 0.441 \\
\hline $\begin{array}{l}\text { Roles and } \\
\text { responsibility }\end{array}$ & $\begin{array}{c}9.19 \\
(4.05) \\
\end{array}$ & $\begin{array}{l}10.66 \\
(3.17) \\
\end{array}$ & $\begin{array}{c}9.36 \\
(3.34) \\
\end{array}$ & $\begin{array}{c}9.58 \\
(3.48) \\
\end{array}$ & $\begin{array}{l}10.07 \\
(3.13) \\
\end{array}$ & $\begin{array}{r}9.65 \\
(3.52) \\
\end{array}$ & 1.971 & 0.098 \\
\hline Overall RIPLS & $\begin{array}{l}75.54 \\
(11.6) \\
\end{array}$ & $77.25(11.30)$ & $\begin{array}{c}75.22 \\
(11.15) \\
\end{array}$ & $77.37(8.46)$ & 77.67 (7.07) & $\begin{array}{c}76.40 \\
(10.30) \\
\end{array}$ & 1.007 & 0.404 \\
\hline $\mathrm{N}$ & 91 & 59 & 107 & 99 & 46 & 402 & & \\
\hline
\end{tabular}

in overall attitudes to IPE among different professions, where some have found no differences ${ }^{21}$ while others have reported differences among professions. ${ }^{13,22}$ The overall high score value in the current study is indicative of positive general attitude of students towards IPE. Several other studies have similarly reported positive attitudes. . $2,13,21,22,24,25$

The subscale analysis of the current results also indicated that the students from all of the health colleges viewed
IPE's role positively in improvement of teamwork and collaboration as well as in shared learning. However, potential areas of differing perceptions of some of the professions pertaining negative identity as well as roles and responsibilities of other professionals, in particular those related to the roles of nurses and therapists were identified. The four subscale scores for each college and total subscale scores for all the colleges combined are shown in Table 3. The mean score ranges were: team- 


\begin{tabular}{|c|c|c|c|c|c|c|c|c|}
\hline \multicolumn{6}{|c|}{ Table 4: Item analysis of the roles and responsibility subscale scores of the five health professional colleges. } \\
\hline Item number & $\begin{array}{c}\text { Nursing } \\
\text { Mean (SD) }\end{array}$ & $\begin{array}{c}\text { Medicine } \\
\text { Mean (SD) }\end{array}$ & $\begin{array}{c}\text { HRS } \\
\text { Mean } \\
\text { (SD) }\end{array}$ & $\begin{array}{c}\text { Pharmacy } \\
\text { Mean (SD) }\end{array}$ & $\begin{array}{c}\text { Dentistry } \\
\text { Mean (SD) }\end{array}$ & $\begin{array}{c}\text { All } \\
\text { Colleges } \\
\text { Mean (SD) }\end{array}$ & F & ANOVA \\
\cline { 3 - 8 } & $3.19(1.52)$ & $3.78(1.20)$ & $\begin{array}{c}3.30 \\
(1.36)\end{array}$ & $3.41(1.28)$ & $3.96(1.17)$ & $3.45(1.35)$ & 3.723 & $0.005^{*}$ \\
\hline 17 & $2.38(1.36)$ & $2.92(1.17)$ & $\begin{array}{c}2.57 \\
(1.32)\end{array}$ & $2.56(1.28)$ & $2.50(1.29)$ & $2.57(1.30)$ & 1.575 & 0.180 \\
\hline 18 & $3.62(1.32)$ & $4.03(1.03)$ & $\begin{array}{c}3.52 \\
(1.11)\end{array}$ & $3.61(1.19)$ & $3.61(1.23)$ & $3.65(1.19)$ & 1.897 & 0.110 \\
\hline 19 & 91 & 59 & 107 & 99 & 46 & 402 & & \\
\hline
\end{tabular}

work and collaboration, 38.7 (HRS) to 40.6 (Dentistry); negative professional identity, 8.9 (Dentistry) to 10.7 (Pharmacy); positive professional identity, 17.2 (HRS) to 18.0 (Dentistry); and roles and responsibility, 9.2 (Nursing) to 10.7 (Medicine). ANOVA did not reveal statistically significant difference among the colleges on the subscales except for that of negative professional identity $(p=0.020)$. Since scoring was reversed for negative statements, greater scores of negative identity subscale also reflect more positive attitude. As indicated in Table 3, Pharmacy scored 10.7, which is the highest, followed by HRS (10.3), Medicine (9.6), Nursing (9.5) and Dentistry (8.9). Post-hoc analysis of this subscale (negative professional identity) for each profession against the others revealed that Pharmacy's score was significantly higher (indicating more positive attitude, as the scores were reversed for this subscale during analysis) than that of Dentistry $(P=0.004)$ and Nursing $(P=0.019)$; and HRS's score was also higher than that of Dentistry $(P=0.024)$. No other college comparisons that were performed within this subscale were significantly different. The relatively low scores of Dentistry followed by Nursing could be indicative of conformity with statements of this sub-scale reflecting isolationist attitudes. In this regard, Pharmacy and HRS students were more inclined to disagree with isolationist statements; and Medical students being in the middle of the score range showed no significant difference with any of the other professions. Pharmacy students' high score in this subscale may be related to the understanding of their professional role as drug experts that would require integrating their work with many different health care professionals. A high score of this subscale in the HRS College may also relate to the various departments in that college which have to integrate their work with different professions. However, further study of the departments in the HRS College is needed to identify the attitudes in the individual departments. Overall, the significant differences among the various professions in this subscale could be suggestive of the need of further qualitative study, in particular in those professions which have scored low (dentistry and nursing) in this subscale, to better understand the issue of negative professional identity and its causes. Educators developing IPE initiatives need to take this into account, as professional identity is vital for the creation of an effective healthcare team.

On the fourth subscale, that is "roles and responsibility", Table 3 shows that the highest mean score was that of Medicine (10.66) followed by Dentistry (10.07), Pharmacy (9.58), HRS (9.36) and Nursing (9.19). When these scores were compared among the colleges using ANOVA, there was no statistically significant difference $(p=0.098)$. With such $p$ value and with the fact that the fourth subscale of the RIPLS suffers from weak internal consistency which is widely reported, ${ }^{13,23,26,27}$ we decided to analyze the individual items of this subscale (items 17, 18 and 19), which could possibly reveal differences in perception on roles and responsibilities. As indicated in Table 4, ANOVA revealed significance $(p=0.005)$ on RIPLS item 17 among the colleges, with no significant difference on the other two items. Since item 17 on the RIPLS, specifically focuses on roles and responsibilities of nurses and therapists, further post hoc analysis on this item was conducted to evaluate for any difference among the professions in their perceptions regarding this aspect. As shown in Table 5, the results revealed that Nursing scores were significantly lower (indicating disagreement) than those of Medicine $(p=0.01)$ and Dentistry $(p=0.002)$; HRS scores (which include the departments of therapists and allied health programs) were also lower than those of Medicine $(p=0.029)$ and Dentistry $(p=0.006)$, also indicating disagreement. Since the College of HRS is comprised of four departments offering many different specialties such as physiotherapy, audiology, radiography, clinical nutrition and more, the roles and responsibility score is a composite of those students in the various specialties in this college and the individual specialty responses might differ. Furthermore, 


\begin{tabular}{|c|c|c|c|}
\hline \multicolumn{5}{|c|}{ Table 5: Post-Hoc LSD analysis of the mean scores of item 17 among the five } \\
health professional colleges. \\
\hline \multicolumn{2}{|c|}{ Colleges compared } & Mean Difference (95\% Cl) & P-value \\
\hline \multirow{2}{*}{ Nursing } & Medicine & $-0.587(-1.03--0.14)$ & $0.010^{*}$ \\
& HRS & $-0.106(-0.48-0.27)$ & 0.581 \\
& Pharmacy & $-0.225(-0.61-0.16)$ & 0.249 \\
& Dentistry & $-0.768(-1.25--0.29)$ & $0.002^{*}$ \\
\hline Medicine & Nursing & $0.587(0.14-1.03)$ & $0.010^{*}$ \\
& HRS & $0.481(0.05-0.91)$ & $0.029^{*}$ \\
& Pharmacy & $0.362(-0.07-0.80)$ & 0.103 \\
& Dentistry & $-0.181(-0.70-0.34)$ & 0.495 \\
\hline HRS & Nursing & $0.106(-0.27-0.48)$ & 0.581 \\
& Medicine & $-0.481(-0.91--0.05)$ & $0.029^{*}$ \\
& Pharmacy & $-0.119(-0.49-0.25)$ & 0.527 \\
& Dentistry & $-0.661(-1.13--0.20)$ & $0.006^{*}$ \\
\hline Pharmacy & Nursing & $0.225(-0.16-0.61)$ & 0.249 \\
& Medicine & $-0.362(-0.80-0.07)$ & 0.103 \\
& HRS & $0.119(-0.25-0.49)$ & 0.527 \\
& Dentistry & $-0.542(-1.01--0.07)$ & $0.024^{*}$ \\
\hline Dentistry & Nursing & $0.768(0.29-1.25)$ & $0.002^{*}$ \\
& Medicine & $0.181(-0.34-0.70)$ & 0.495 \\
& HRS & $0.661(0.20-1.13)$ & $0.006^{*}$ \\
& Pharmacy & $0.542(0.07-1.01)$ & $0.024^{*}$ \\
\hline
\end{tabular}

Pharmacy scores were lower than Dentistry $(p=0.024)$. Overall, analysis of this item on the roles and responsibility subscale suggested that there were differences of opinion between the students of medicine and dentistry on the one hand and nursing and HRS students on the other, on what the roles and responsibilities of nurses and therapists are. Student of nursing and HRS did not agree that their job is to mainly offer support to doctors, while medical and dental students' perception of the role of nurses and therapists was that of providing help to doctors. It was interesting to see that pharmacy students' perception agreed more with those of the nursing and HRS students indicating more awareness of what the roles of these professions are. Differences in awareness of professional roles and responsibilities were highlighted in previous studies ${ }^{21}$ including one focusing on students of dentistry, dental hygiene and dental nursing which has revealed similar misconceptions of roles and responsibilities. ${ }^{28}$ This study suggested that attitudes in support of partnership in care rather than subordinate roles of some professions should be encouraged to promote success in interprofessional care. Students should be trained to recognize their roles, responsibilities and professional boundaries as well as to appreciate those of the other professions in the team, which would contribute to the success of a healthcare team work. From the current results, it seems that more effort needs to be made in imparting the right attitude regarding the roles and responsibilities among students on the various health professions and IPE can be used as one of the modalities to implement such objective. The current study, thus highlights this important issue to be considered by those involved in the development of IPE programs. We also recommend that roles and responsibility issues need further assessment using a separate questionnaire possibly including qualitative assessment.

Two of the demographic parameters namely students' age and year of study were tested for possible correlation between the RIPLS scores. Pearson correlation analysis of overall RIPLS score and scores of the four subscales with year of study revealed no statistically significant relationships ( $\mathrm{r}$ ranging between -0.083 and 0.079 and $p$ ranging between 0.098 and 0.894$)$. Similarly, no significant relationship was found between the RIPLS scores and the four age groups ( $\mathrm{r}$ ranging between -0.027 and 0.078 and $p$ ranging between 0.121 and 0.873 ). Thus, in the current study, none of the attitude scores were correlated with age or year of study. Some earlier studies have reported RIPLS scores not being significantly affected by demographic variables, ${ }^{22}$ while others showing correlation with some demographic variables ${ }^{13,29}$ including gender. ${ }^{25}$ A limitation in our study which could probably have masked a possible correlation of RIPLS scores with year of study or age could be the proportion of respondents in the $4^{\text {th }}$ and $5^{\text {th }}$ professional years which was low, since not all the programs offer 4 and 5 years of professional study and the response rates of those in the higher levels was also low. Another limitation to our study could be that we were unable to have gender 
comparisons because the study was conducted in an all-female university.

\section{CONCLUSION}

This study demonstrated an overall strong readiness and positive perception of students of the various health professions towards IPE. In addition, the study provided a useful insight into differences among some of the professions with respect to professional identities and roles and responsibilities, which could be potential barriers to the realization of IPE. Further research would be required to explore the roots of such behaviors and their mitigation. These findings could be used to inform educators and stakeholders in the proper design and implementation of IPE.

\section{ACKNOWLEDGEMENT}

The authors acknowledge Dr. Amel Fayed from the College of Medicine, Princess Nourah University for her contribution to the statistical methods. This research was funded by the Deanship of Scientific Research at Princess Nourah bint Abdulrahman University through the Fast-track Research Funding Program.

\section{CONFLICT OF INTEREST}

The authors declare no conflict of interest.

\section{ABBREVIATIONS}

IPE: Interprofessional education; RIPLS: Readiness for Interprofessional Learning Scale; HRS: Health and Rehabilitation Sciences

\section{REFERENCES}

1. Hepler CD, Strand LM. Opportunities and responsibilities in pharmaceutical care. Am J Hosp Pharm. 1990;47(3):533-43. doi: 10.1093/ajhp/47.3.533, PMID 2316538.

2. Barr H, Koppel I, Reeves S, Hammick M, Freeth D. Effective interprofessional education: argument, assumption and evidence. Oxford, UK: Blackwell Publishing; 2005.

3. Buring SM, Bhushan A, Broeseker A, Conway S, Duncan-Hewitt W, Hansen L, Westberg S. Interprofessional education: definitions, student competencies, and guidelines for implementation. Am J Pharm Educ. 2009;73(4):Article 59. doi: 10.5688/aj730459. Cited in Buring SM, PMID, Bhushan A, Broeseker A, Conway S, Duncan-Hewitt W, Hansen L, Westberg S. Am J Pharm Educ. 2009;73(4):59. doi: 10.5688/aj730459, PMID 19657492.

4. Yan J, Gilbert J, Hoffman SJ. World Health Organization Study Group on Interprofessional Education and Collaborative Practice [announcement]. J Interprof Care. 2008;21(6):588-9.

5. World Health Organization. [Homepage on the Internet]; 2010. Framework for action on interprofessional education and collaborative practice. Available from: https://www.who.int/hrh/resources/framework_action/en/ [cited 28/5/2021].

6. Hammick M, Freeth D, Koppel I, Reeves S, Barr H. A best evidence systematic review of interprofessional education: BEME Guide no. 9. Med
Teach. 2007;29(8):735-51. doi: 10.1080/01421590701682576, PMID 18236271.

7. Orbayinah S, Utami LP. Impact of interprofessional education on collaboration attitudes among the students of medical faculty and health sciences universitas Muhammadiyah Yogyakarta. J Health Med Nurs. 2015;17:97-100.

8. Hoffman SJ, Harnish D. The merit of mandatory interprofessional education for pre-health professional students. Med Teach. 2007;29(8):e235-42. doi: 10.1080/01421590701551672, PMID 18236267.

9. Greiner AC, Knebel E, editors. Health professions education: A bridge to quality. Institute of Medicine committee on the health professions education. Summit, Washington, DC: National Academy Press; 2003.

10. Fallatah HI, Jabbad R, Fallatah HK. Interprofessional Education as a Need: The Perception of Medical, Nursing Students and Graduates of Medical College at King Abdulaziz University. Creat Educ. 2015;06(2):248-54. doi: 10.4236/ce.2015.62023.

11. Al-Eisa E, Alderaa A, AlSayyad A, AlHosawi F, AlAmoudi S, AlTaib S, Mahmoud S, AIGhanim T, Alghadir A, Anwer S. The perceptions and readiness toward interprofessional education among female undergraduate health-care students at King Saud University. J Phys Ther Sci. 2016;28(4):1142-6. doi: 10.1589/jpts.28.1142, PMID 27190442.

12. Wilbur K, Kelly I. Interprofessional impressions among nursing and pharmacy students: A qualitative study to inform interprofessional education initiatives. BMC Med Educ. 2015;15(1):53. doi: 10.1186/s12909-015-0337-y, PMID 25888947.

13. Al-Qahtani MF. Measuring healthcare students' attitudes toward interprofessional education. J Taibah Univ Med Sci. 2016;11(6):579-85. doi: 10.1016/j.jtumed.2016.09.003.

14. El-Awaisi A, Wilby KJ, Wilbur K, ElHajj MS, Awaisu A, Paravattil B. A Middle Eastern journey of integrating Interprofessional Education into the healthcare curriculum: a SWOC analysis. BMC Med Educ. 2017;17(1):15. doi: 10.1186/ s12909-016-0852-5, PMID 28095829.

15. Davidson M, Smith RA, Dodd KJ, Smith JS, O'Loughlan MJ. Interprofessional pre-qualification clinical education: a systematic review. Aust Health Review. 2008;32(1):111-20. doi: 10.1071/AH080111.

16. Remington TL, Foulk MA, Williams BC. Evaluation of evidence for interprofessional education. Am J Pharm Educ. 2006;70(3):66. doi: 10.5688/ aj700366, PMID 17136186.

17. Eksteen MJ, Reitsma GM, Swart SB, Fourie E. Team-based learning experiences of fourth-year pharmacy students in a South African university. Am J Pharm Educ. 2018;82(1):6167. doi: 10.5688/ajpe6167, PMID 29491498.

18. Wilbur K, Hasnani-Samnani Z, Kelly I. Interprofessionaleducation activity among undergraduate nursing and pharmacy students in the Middle East. Nurse Educ. 2015;40(4):163-4. doi: 10.1097/NNE.0000000000000135, PMID 25628246.

19. El-Awaisi A, Saffouh El Hajj M, Joseph S, Diack L. Interprofessional education in the Arabic-speaking Middle East: perspectives of pharmacy academics. J Interprof Care. 2016;30(6):769-76. doi: 10.1080/13561820.2016.1218830, PMID 27705033.

20. Rudland JR, Mires GJ. Characteristics of doctors and nurses as perceived by students entering medical school: implications for shared teaching. Med Educ. 2005;39(5):448-55. doi: 10.1111/j.1365-2929.2005.02108.x, PMID 15842678.

21. Horsburgh M, Lamdin R, Williamson E. Multiprofessional learning: the attitudes of medical, nursing and pharmacy students to shared learning. Med Educ. 2001;35(9):876-83. doi: 10.1046/j.1365-2923.2001.00959.x, PMID 11555226.

22. Ahmad MI, Chan SW, Wong LL, Tan ML, Liaw SY. Are first-year healthcare undergraduates at an Asian university ready for interprofessional education? J Interprof Care. 2013;27(4):341-3. doi: 10.3109/13561820.2013.769094, PMID 23421343.

23. McFadyen AK, Webster V, Strachan K, Figgins E, Brown H, McKechnie J. The Readiness for Interprofessional Learning Scale: a possible more stable sub-scale model for the original version of RIPLS. J Interprof Care. 2005;19(6):595-603. doi: 10.1080/13561820500430157, PMID 16373215.

24. El-Awaisi A, El-Hajj MS, Joseph S, Diack L. Perspectives of Pharmacy students in Qatar toward interprofessional education and collaborative practice: a mixed methods study. J Interprof Care. 2018;32(6):674-88. doi: 10.1080/13561820.2018.1498466, PMID 30052106. 
25. Khan TM, Madu Emeka P, Aljadhey H, Haseeb A. Study investigating pharmacy students' interprofessional perceptions toward the pharmacy profession in Saudi Arabia. Curr Pharm Teach Learn. 2015;7(1):62-9. doi: 10.1016/j.cptl.2014.09.019.

26. Mahler C, Rochon J, Karstens S, Szecsenyi J, Hermann K. Internal consistency of the readiness for interprofessional learning scale in German health care students and professionals. BMC Med Educ. 2014;14:article 145. doi: 10.1186/1472-6920-14-145, PMID 25027384.

27. Tamura Y, Seki K, Usami M, Taku S, Bontje P, Ando H, Taru C, Ishikawa Y. Cultural adaptation and validating a Japanese version of the readiness for interprofessional learning scale (RIPLS). J Interprof Care. 2012;26(1):56-63. doi: 10.3109/13561820.2011.595848, PMID 22233369.

28. Morison S, Marley J, Stevenson M, Milner S. Preparing for the dental team: investigating the views of dental and dental care professional students. Eur J Dent Educ. 2008; Feb;12(1):23-8. doi: 10.1111/j.1600-0579.2007.00487.x, PMID 18257761.

29. Curran VR, Sharpe D, Forristall J, Flynn K. Attitudes of health sciences students towards interprofessional teamwork and education. Learn Health Soc Care. 2008;7(3):146-56. doi: 10.1111/j.1473-6861.2008.00184.x.

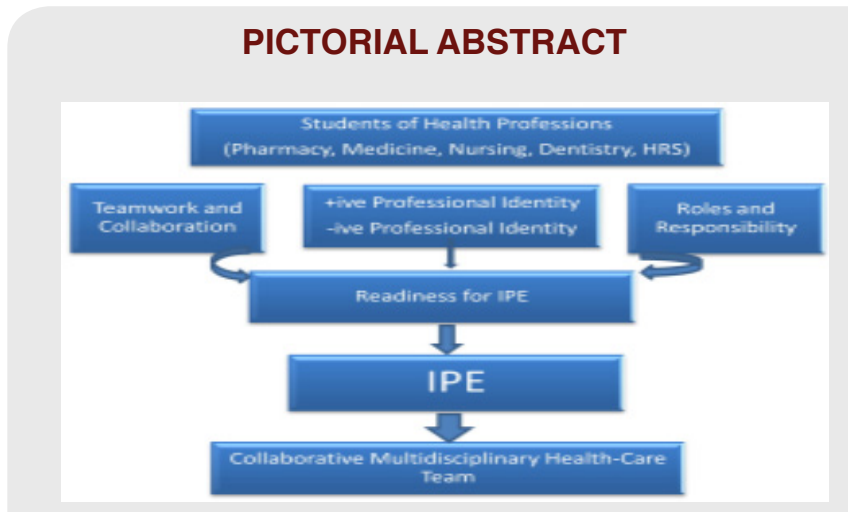

\section{SUMMARY}

- Interprofessional education (IPE) equips students with a background for multidisciplinary collaboration in health care provision.

- Assessment of perceptions of students of five health professional colleges, including Pharmacy, towards IPE utilizing the 19-item RIPLS survey with four subscales revealed that overall students' attitude was positive suggesting their readiness.

- Differences in perceptions of professional identity and roles and responsibilities among some professions require attention of educators since understanding of such attributes is vital for creating effective healthcare teams.

\section{About Authors}

Dr. Azieb Ogbaghebriel is a Professor of Pharmacology at the Department of Pharmaceutical Sciences of the College of Pharmacy, Princess Nourah bint Abdulrahman University, Riyadh, KSA. She has extensive teaching and research experience in Pharmacy and related disciplines in various parts of the world, including in the Middle East, North America and Africa.

Dr. Jude AlHuweidi is a Pharm.D. graduate from the College of Pharmacy at Princess Nourah bint Abdulrahman University. She is currently doing her residency at the Clinical Pharmacy Department of King Fahad Medical City, Riyadh, KSA.

Dr. Raneem AlZeer: is a Pharm.D. graduate from the College of Pharmacy at Princess Nourah bint Abdulrahman University, KSA. Currently, she is a Teaching Assistant at the Department of Pharmacy Practice of the College of Pharmacy at the same University.

Cite this article: Ogbaghebriel A, AlHuwaidi J, AIZeer R. Perceptions of Pharmacy and Other Health Professional Students toward Interprofessional Education. Indian J of Pharmaceutical Education and Research. $2021 ; 55(3): 916-23$. 